\title{
Small intestinal morphology in experimental diabetic rats: a stereological study on the effects of an aldose reductase inhibitor (ponalrestat) given with or without conventional insulin therapy
}

\author{
T.M. Mayhew, F. L. Carson and A. K. Sharma \\ Department of Anatomy, Marischal College, University of Aberdeen, Aberdeen, Scotland
}

\begin{abstract}
Summary. The gross and microscopical dimensions of small intestines from 12-week old streptozotocin-diabetic rats receiving no therapeutic intervention were compared with those from animals receiving insulin alone or in conjunction with the aldose reductase inhibitor, ponalrestat. Four regions along each intestine were analysed stereologically. Insulin had significant beneficial effects on body weight as well as on intestinal length, width, surface area and volume. In contrast, ponalrestat did not improve body weight deficits and was associated with crypt hypertrophy and a reduced villous surface/crypt volume ratio. There were interaction effects between insulin and ponalrestat for intestinal length and primary mucosal surface area. All groups displayed significant regional differences
\end{abstract}

in surface area of primary mucosa and volume of muscularis externa. Only untreated diabetic rats failed to reveal regional variation in the surface area and volume of villi. Ratios of villous surface area/crypt volume varied from region-to-region in insulin-treated diabetic rats but not in other groups. The study fails to reveal any beneficial effect of aldose reductase inhibition on the changes in intestinal morphology seen in experimental diabetes.

Key words: Diabetes mellitus, insulin injection, aldose reductase inhibitor, small intestine, villi, crypts, muscularis externa, stereology.
Experimental diabetes mellitus, induced by streptozotocin (STZ) or by alloxan, leads to an elevated absorption of glucose and amino acids by the small intestine. The increases occur both in vitro and in vivo [1-5]. Increased absorption of glucose seems to be a two-stage response. An initial rapid rise in glucose transport rate occurs within hours of the onset of diabetes, before any morphological changes are demonstrable. This stage is superseded by a slower rise which begins during the first week of diabetes and involves growth in intestinal mass $[2,4,6]$.

The changes in intestinal mass are due to increases in intestinal length, diameter and mucosal mass $[2,4,7]$. By light microscopy, these alterations are seen to correspond, in part, with the presence of taller villi and deeper crypts $[8,9]$. Biochemical and kinetic studies have shown that these arise mainly by hyperplasia but with some cellular hypertrophy $[9,10]$. Changes in morphology and in enzymic activity may also occur at the microvillous brush-border of absorptive epitheliocytes $[5,8,11]$.

In a previous study [12], we confirmed the structural changes as part of a continuing investigation into the effects of alternative therapeutic interventions on the morphology of peripheral nerves [13], kidneys [14-16] and intestines [17] in STZ-diabetic rats. We found [12] that the intestines of untreated diabetic rats were wider than those of age-matched control rats with greater surface areas and volumes of villi and with greater volumes of submucosa (including crypts) and muscularis externa. The heights of the villi in ileal segments were increased preferentially (so that the villi altered shape) and the regional differences in villous surfaces seen along the intestines of control rats were minimised.

In this paper, we report the effects on intestinal morphology of an aldose reductase inhibitor, ponalrestat, given to STZ-diabetic rats either alone or in conjunction with conventional insulin therapy (CIT). Earlier studies on peripheral nerves from these animals [13] have shown that ponalrestat can correct biochemical abnormalities (elevated sorbitol and fructose and decreased myo-inositol concentrations within sciatic nerves) without any significant beneficial impact on structural abnormalities (excess axonal degeneration and reduced fibre and axon profille areas). 


\section{Materials and methods}

\section{Experimental groups and tissue preparation}

Details of animals and procedures used are given in previous reports $[12,13]$. We began with 60 male Sprague-Dawley rats (age 11 weeks; body weight $350-550 \mathrm{~g}$ ). These were maintained in plastic cages on a $14 \mathrm{~h}-10 \mathrm{~h}$ light-dark cycle and allowed unrestricted access to a standard pellet diet and to drinking water. They were divided into six experimental groups of equal size and roughly equal mean body weight.

Animals in one group (onset control rats) were killed at 11 weeks of age for baseline information on this strain, age and body weight. Age-matched control rats were weighed for the last time at 23 weeks and then killed. Four additional groups were studied over a 12 -week period after induction of diabetes by an i.p. injection of buffered STZ under ether anaesthesia (dosage $49-67 \mathrm{mg} / \mathrm{kg}$ body weight). At the end of 12 weeks, these animals also were weighed for the last time and killed. The four groups comprised: untreated diabetic rats (UD), diabetic rats treated with daily s.c. injections of Ultralente insulin (CITD), those treated with ponalrestat (ICI, Macclesfield, UK) (ARID) and those treated with insulin and ponalrestat (CIT/ARID). Ponalrestat was administered daily by gavage and at a dosage of $25 \mathrm{mg} / \mathrm{kg}$ body weight [13].

Details of blood glucose analyses undertaken on these animals are provided elsewhere [13] and so will be summarised only. For UD rats and age-matched control rats blood glucose analyses were made at weekly intervals. For other groups of diabetic animals, daily blood glucose levels were recorded.

Present results are confined to those obtained from all the diabetic animals (the final numbers of which are given in Table 1). Comparisons between onset and age-matched control rats, and between agematched control and UD rats are given in an earlier paper [12]. For the sake of completeness, and to facilitate biological interpretation, values obtained for age-matched control rats are given here in summary.

In order to minimise the influence of circadian variation, animals were killed under ether anaesthesia between 09.30 hours and 12.30 hours. They were killed by intra-cardiac perfusion of an isotonic (154 mmol/l) NaCl pre-wash followed by $2.5 \%$ phosphate-buffered glutaraldehyde ( $\mathrm{pH}$ 7.3). Both solutions were delivered by simple gravity feed $(90-100 \mathrm{~mm} \mathrm{Hg})$ at room temperature.

\section{Tissue sampling procedures}

Following primary fixation each small intestine was cut at the pylorus and at the ileocaecal junction, freed of attached mesentery and removed. Total length was then estimated on a horizontal workbench using a scale marked with $1 \mathrm{~cm}$ intervals.

Each intestine was sliced into four segments of approximately equal length. Each segment was further cut into smaller pieces from which four were selected at random (by lottery). Luminal contents were flushed away with fresh fixative and each piece was trimmed to a length of about $2 \mathrm{~cm}$. The four pieces from each segment were then immersed in fixative prior to post-fixation in $1 \%$ phosphate-buffered osmium tetroxide and dehydration in graded concentrations of ethyl alcohol. Pieces were embedded in araldite resin so that complete transverse sections of intestine could be cut $[12,18-20]$.

One block, chosen by lottery, was taken to represent each intestinal segment. From each block, one arbitrarily located thin section (nominal thickness 1-4 $\mu \mathrm{m}$ ) was cut using glass knives (suitable for CITD and CIT/ARID intestines) or stainless steel blades (required for the greatly distended UD and ARID intestines). These transverse sections were stained with toluidine blue.

Each transverse section was projected onto drawing paper to give a flat and undistorted image. Final linear magnifications varied between $\times 39$ and $\times 72$, estimated using micrometer scale standards. The outlines of the primary mucosa (defined as the interface running between the bases of villi and the openings of crypts), villi, interface between submucosa and muscularis externa and interface between muscularis and serosa were then traced.

\section{Morphometry}

Tracings were analysed by stereological methods, full details of which are provided elsewhere $[12,18-20]$. Segmental estimates of primary mucosal and villous surface areas were derived by intersection counting [21] using test lattices with squares of edge length $1 \mathrm{~cm}$ (CITD and CIT/ARID groups) and $3 \mathrm{~cm}$ (UD and ARID groups). Lattices were superimposed on tracings in such a way as to be independent random in both position and orientation. The method of estimating villous surface area [18] relies on the use of a geometric model and so is not unbiased in general. However, recent studies on normal intestines have shown that the model can generate acceptable estimates [22].

Volumes of villi, submucosa, crypts and muscularis externa were estimated from transverse sections by point counting [21] using randomly positioned (orientation is unimportant) $1 \mathrm{~cm}$ test lattices. Volume of muscularis externa was chosen in preference to thickness which is an unsatisfactory index of muscle mass [12].

To assess the relationship between the proliferative (crypt) and non-proliferative (villous) compartments of the intestinal epithelium, we estimated the ratio of villous surface area/crypt volume [12]. The surface area occupied by the apex of each epitheliocyte varies less over the villus than cell height and, in any case, villous volume includes the volume of lamina propria and not just that of the villous epithelium. Therefore, villous surface area is expected to correlate better with cell number than with villous volume. Crypt volume may also be regarded as a convenient relative index of crypt cellularity.

To estimate total surfaces (S) and volumes (V) per intestine, we simply added corresponding segmental values. Overall villous 'shape" in each intestine was quantified using the dimensionless coefficient $\left(\mathrm{S}^{1.5}\right) / \mathrm{V}$. This coefficient is independent of villous size in the sense that it is constant for isomorphic objects (i.e. having the same shape but possibly different sizes). The coefficient will be constant provided that villous shape does not alter between experimental groups. It depends also on villous number but this is fixed over most of the lifespan in rats $[23,24]$.

Segmental estimates of mean perimeter length of the primary mucosa (proportional to mean cross-sectional 'diameter' at this interface) were also obtained by intersection counting $[18,19]$. The mean perimeter length for the intestine as a whole was estimated by dividing total surface of primary mucosa per intestine by intestinal length.

\section{Statistical analysis}

For segmental and total intestinal values, we calculated group means and standard errors (SEM). Segmental variation within intestines was analysed using Page's 'L' trends test for related samples [25]. This is a non-parametric test applicable to $n$ subjects (rats) in $\mathrm{k}$ samples (intes-

Table 1. Body weight, intestinal length and intestinal perimeter in the four groups of streptozotocin-diabetic rats. Values are group means (SEM)

\begin{tabular}{|c|c|c|c|c|}
\hline \multirow[t]{2}{*}{ Variable } & \multicolumn{4}{|c|}{ Experimental groups: } \\
\hline & $\begin{array}{l}\text { UD } \\
(n=7)\end{array}$ & $\begin{array}{l}\text { CITD } \\
(n=10)\end{array}$ & $\begin{array}{l}\text { ARID } \\
(n=8)\end{array}$ & $\begin{array}{l}\text { CIT/ARID } \\
(n=9)\end{array}$ \\
\hline $\begin{array}{l}\text { Body weight (g) } \\
\text { Intestinal }\end{array}$ & 316 & $635(11.7)$ & $320(25.0)$ & $547(29.3)$ \\
\hline $\begin{array}{l}\text { length }(\mathrm{cm}) \\
\text { Intestinal }^{\mathrm{a}}\end{array}$ & 121 (3.32) & $110 \quad(2.73)$ & $133 \quad(2.89)$ & $101 \quad(3.63)$ \\
\hline perimeter $(\mathrm{mm})$ & $18 \quad(0.98)$ & $12(0.34)$ & $18(0.90)$ & $11 \quad(0.28)$ \\
\hline
\end{tabular}

UD - untreated diabetic rats; CITD - insulin treated rats; ARID - ponalrestat treated rats; CIT/ARID - insulin and ponalrestat treated rats; ${ }^{a}$ perimeter is mean for the entire small intestine; Two-way analyses of variance revealed significant effects of ponalrestat on body weight $(p<0.01 ;$ df 1,30$)$ and insulin on weight, length and perimeter (all $p<0.001 ; \mathrm{df} 1,30$ ). There was also a significant insulin $\times$ ponalrestat interaction involving intestinal length $(p<0.01 ; \mathrm{df} 1,30)$ 
tinal regions). Differences between experimental groups were assessed using two- and three-way analyses of variance [26]. To compare body weights, intestinal lengths and villous 'shape' coefficients, we employed two-way analyses of variance with insulin (presence or absence) and ponalrestat (presence or absence) as the two factors. The first-order interaction term generated by this test provided an indication of the degree of synergism/antagonism between the two factors. To compare other variables, we used three-way analyses of variance with insulin, ponalrestat and intestinal region as the main effects. This test generates three first-order interaction terms and one second-order interaction term.

For all statistical tests, a $p$ value of $>0.05$ was taken to indicate no statistically significant effect/difference.

\section{Results}

Plasma glucose levels in UD rats varied from 26 to $35 \mathrm{mmol} / \mathrm{l}$ (mean $30 \mathrm{mmol} / \mathrm{l}$ ) and were not significantly different in ARID rats. Thus, ponalrestat had no beneficial influence on blood glucose concentrations. Satisfactory control of blood glucose levels within the normal range $(3.5-7 \mathrm{mmol} / 1)$ was achieved in CITD animals. Good glycaemic control was more difficult to achieve in CIT/ARID animals and short episodes of hypo- and hyper-glycaemia occurred in a few animals but not on more than two consecutive days.

\section{Body weight, intestinal length, intestinal perimeter}

Mean body weight (SEM) in age-matched control animals was $648 \mathrm{~g}(12.3 \mathrm{~g})$. Corresponding values for intestinal length and overall perimeter were $114 \mathrm{~cm}(2.5 \mathrm{~cm})$ and $11.1 \mathrm{~mm}(0.3 \mathrm{~mm})$, respectively. The values for UD, CITD, ARID and CIT/ARID animals are provided in Table 1.

Mean body weight in UD rats was roughly half of that in age-matched control rats whilst mean intestinal perimeter was significantly greater $(p<0.001)$. The apparent increase in intestinal length was not statistically significant.

Body weights were significantly affected by CIT $(p<0.001)$ and by ponalrestat $(p<0.01)$ and there was no interaction effect. Body weights were normalised in CITD rats but only partially corrected when insulin was administered in conjunction with ponalrestat. Ponalrestat administered alone produced no improvement in body weight.

Intestinal lengths were influenced significantly by CIT $(p<0.001)$ but not by ponalrestat. However, there was an interaction effect $(p<0.01)$. In the CITD group, intestinal length was normal whilst ARID rats tended to possess longer intestines. In the CIT/ARID rats, intestinal lengths tended to be shorter.

The mean perimeter length of intestines was also influenced significantly by CIT $(p<0.001)$ but not by ponalrestat. Nor was there any interaction effect. CIT normalised perimeters but ponalrestat had no beneficial effect.

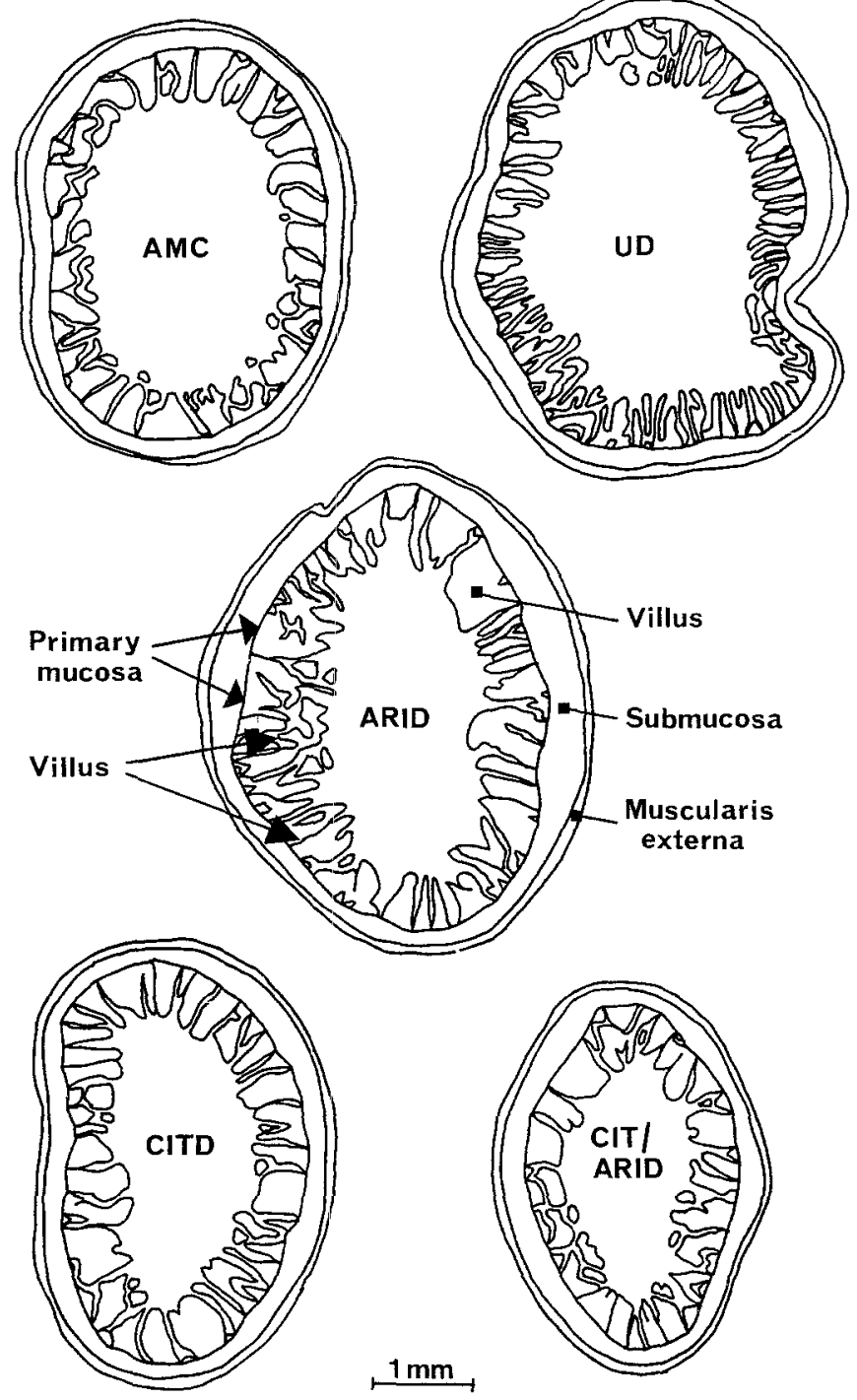

Fig. 1. Comparison of traces of complete transverse sections through equivalent zones (zone 2, jejunum) of diabetic rats and age-matched control rats (AMC). Diabetic rats were either untreated (UD), given ponal restat alone (ARID), given insulin alone (CITD) or given insulin and ponalrestat (CIT/ARID). The main tissue compartments (villus, submucosa, muscularis externa) and surfaces (primary mucosa, villus) are indicated on the central tracing

\section{Microscopical morphometry}

Tracings of complete tranverse sections from proximal regions of small intestines are illustrated in Figure 1.

1. Regional variation along the intestine. In agematched control rats mean surface areas for primary mucosa and villi were $126 \mathrm{~cm}^{2}\left(5.46 \mathrm{~cm}^{2}\right)$ and $680 \mathrm{~cm}^{2}$ $\left(22.9 \mathrm{~cm}^{2}\right)$, respectively whilst component volumes amounted to $3084 \mathrm{~mm}^{3}\left(157 \mathrm{~mm}^{3}\right)$ for villi, $2566 \mathrm{~mm}^{3}$ $\left(120 \mathrm{~mm}^{3}\right)$ for subrnucosa, $704 \mathrm{~mm}^{3}\left(38.8 \mathrm{~mm}^{3}\right)$ for crypts and $765 \mathrm{~mm}^{3}\left(32.9 \mathrm{~mm}^{3}\right)$ for muscularis externa. There were significant regional fluctuations in all variables except crypt volume. Moreover, all surface areas and volumes were increased in UD animals.

All diabetic intestines demonstrated significant regional differences in some, but not all, variables. Re- 
Table 2. Results of Page's ' $L$ ' test applied to observed regional estimates of structural quantities

\begin{tabular}{lllll}
\hline Variable & \multicolumn{4}{l}{ Experimental groups: } \\
\cline { 2 - 5 } & UD & CITD & ARID & CIT/ARID \\
\hline $\mathrm{B}(\mathrm{pm})$ & $p<0.01$ & $p<0.01$ & $p<0.01$ & $p<0.05$ \\
$\mathrm{~S}(\mathrm{pm})$ & $p<0.01$ & $p<0.01$ & $p<0.01$ & $p<0.05$ \\
$\mathrm{~S}(\mathrm{v})$ & $\mathrm{NS}$ & $p<0.01$ & $p<0.05$ & $p<0.05$ \\
$\mathrm{~V}(\mathrm{v})$ & $\mathrm{NS}$ & $p<0.01$ & $p<0.01$ & $p<0.01$ \\
$\mathrm{~V}(\mathrm{sm})$ & $\mathrm{NS}$ & $\mathrm{NS}$ & $p<0.01$ & $p<0.05$ \\
$\mathrm{~V}(\mathrm{cr})$ & $p<0.01$ & $\mathrm{NS}$ & $p<0.05$ & $\mathrm{NS}$ \\
$\mathrm{V}(\mathrm{me})$ & $p<0.05$ & $p<0.05$ & $p<0.01$ & $p<0.05$ \\
$\mathrm{~S}(\mathrm{v}) / \mathrm{V}(\mathrm{cr})$ & $\mathrm{NS}$ & $p<0.01$ & $\mathrm{NS}$ & $\mathrm{NS}$ \\
\hline $\mathrm{B}$
\end{tabular}

$\mathrm{B}=$ perimeter length; $\mathrm{S}=$ surface area; $\mathrm{V}=$ volume; $(\mathrm{cr})=$ crypts; $(\mathrm{me})=$ muscularis externa; $(\mathrm{pm})=$ primary mucosa $;(\mathrm{sm})=$ submucosa; $(v)=$ villi; $U D=$ untreated diabetic rats; $C I T D=$ insulin treated rats; $A R I D=$ ponalrestat treated rats; $C I T / A R I D=$ insulin and ponalrestat treated rats; $\mathrm{NS}=$ not significant

Table 3. Summary of structural quantities in the intestines of streptozotocin-diabetic animals. Values are group means (SEM) for the entire small intestine

\begin{tabular}{|c|c|c|c|c|}
\hline \multirow[t]{2}{*}{ Variable } & \multicolumn{4}{|c|}{ Experimental groups: } \\
\hline & UD & CITD & ARID & CIT/ARID \\
\hline \multicolumn{5}{|c|}{ a. Surface areas, $\mathrm{cm}^{2}$} \\
\hline $\mathrm{S}(\mathrm{pm})$ & $215(14.7)$ & $130(4.88)$ & $235(12.4)$ & $108(5.39)$ \\
\hline$S(v)$ & $1356(93.5)$ & $703(32.7)$ & $1266(56.5)$ & $579(34.5)$ \\
\hline \multicolumn{5}{|c|}{ b. Volumes, $\mathrm{mm}^{3}$} \\
\hline $\mathrm{V}(\mathrm{v})$ & $5827(378)$ & $3457(353)$ & $6272(295)$ & $2731(183)$ \\
\hline $\mathrm{V}(\mathrm{sm})$ & $4693(290)$ & $2975(191)$ & $5373(135)$ & $2757(109)$ \\
\hline $\mathrm{V}(\mathrm{cr})^{\mathrm{a}}$ & $1421(106)$ & $760(43.0)$ & $1772(126)$ & $814(49.7)$ \\
\hline$V(\mathrm{me})$ & $1699(123)$ & $993(70.7)$ & $1912(120)$ & $877(47.3)$ \\
\hline \multicolumn{5}{|c|}{ c. Shape factors, $\mathrm{mm}^{3} / \mathrm{mm}^{3}$} \\
\hline Villi & $8590(586)$ & $5544(217)$ & $7252(414)$ & $5114(205)$ \\
\hline \multicolumn{5}{|c|}{ d. Surface/volume ratios, $\mathrm{mm}^{2} / \mathrm{mm}^{3}$} \\
\hline $\mathrm{S}(\mathrm{v}) / \mathrm{V}(\mathrm{cr}$ & $97(5.83)$ & $94(4.59)$ & $75(7.50)$ & $72(4.23)$ \\
\hline
\end{tabular}

${ }^{a}$ crypts form a sub-compartment of the submucosa; UD - untreated diabetic rats; CITD - insulin treated rats; ARID - ponalrestat treated rats; CIT/ARID - insulin and ponalrestat treated rats; $\mathrm{S}=$ surface area; $\mathrm{V}=$ volume; $(\mathrm{cr})=$ crypts; $(\mathrm{me})=$ muscularis externa; $(\mathrm{pm})=$ primary $\operatorname{mucos} a ;(\mathrm{sm})=$ submucosa $;(\mathrm{v})=$ villi

sults of Page's ' $L$ '-tests applied to the regional morphometric data are summarised in Table 2.

In all groups, the only quantities to exhibit consistent regional differences were the perimeter length and surface area of primary mucosa and the volume of muscularis externa. Untreated STZ-diabetes was associated with loss of the normal fluctuations in villous surface area, villous volume, submucosal volume and villous surface/crypt volume ratio but with significant regional variation in crypt volume.

Both forms of intervention, whether given alone or together, preserved most of the pattern of variability witnessed in age-matched control animals.

2. Effects of interventions. In UD rats, all volumes and surfaces were substantially increased, $(p<0.001)$, villi altered shape (the shape factor rose from 5802 to $8590 \mathrm{~mm}^{3} / \mathrm{mm}^{3}$ ) but the villous surface/crypt volume ratio was maintained.
CIT normalised villous shape $(p<0.001)$ whilst ponalrestat administered alone appeared to improve but not normalise villous shape. There was no significant interaction effect.

Other findings for diabetic groups are provided in Table 3. Results of analyses of variance undertaken on these data (Table 4) may be summarised as follows. CIT had beneficial effects on all altered quantities $(p<0.001$ in every case) whilst ponalrestat led to further crypt hypertrophy $(p<0.01)$ which contributed to an increased volume of submucosa $(p<0.05)$ and to a reduced villous surface/crypt volume ratio $(p<0.001)$. Overall, then, ponalrestat showed no beneficial influence on intestinal morphometry in STZ-diabetic rats.

No significant second-order interaction effects were detected. However, there were significant first-order interactions between insulin and ponalrestat as well as between these therapies and intestinal regions. Thus, CIT tended to have greater impact in clistal regions of the small intestine.

\section{Discussion}

This study has shown that major morphological changes in STZ-diabetic rat small intestines are responsive to conventional insulin therapy and that the beneficial effects of insulin vary with position along the intestine. In contrast, aldose reductase inhibition using ponalrestat had no beneficial effects but led to further crypt hypertrophy and, thereby, to a change in the relationship between proliferative (crypt) and non-proliferative (villus) compartments. Again, any effects of ponalrestat tended to be focussed on particular segments. Interaction effects between insulin and ponalrestat were detected.

The correlation between small intestinal morphology and behaviour in experimental diabetes is not perfect. Over the first 3-5 days of experimental diabetes, behavioural alterations precede light microscopical changes and may be localised either at the apical brushborder or at the basolateral plasma membranes of enterocytes $[5,8,11,27,28,30]$.

After this initial period, the correlation between structure and performance is much better. The increase in functional surfaces reported here and elsewhere [12, 29 ] is associated with enhanced $\mathrm{Na}^{+}-$dependent uptake of nutrients whilst $\mathrm{Na}^{+}$-independent uptake is unaltered $[1,30]$. The active uptake of sugars, bile salts and many amino acids is enhanced [1-5] and there is evidence that intestinal transport [31] and cell kinetics [10] in ileal regions of small intestine are affected preferentially. Villous height also increases to greater extents in distal regions [12]. Present findings support this regional impact of STZ to the extent that interaction terms (insulin $X$ intestinal region) were found for all variables and the beneficial effects of insulin were mainly localised distally. 
Table 4. Results of three-way analyses of variance applied to data summarised in Tables 1 and 3

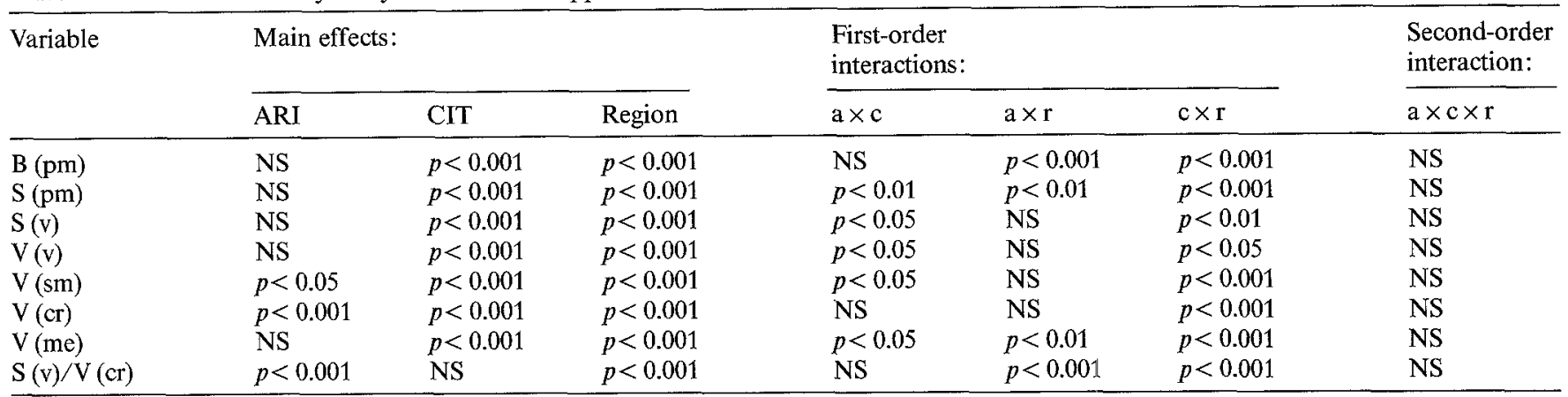

$\mathrm{a} \times \mathrm{c} \times \mathrm{r}$ denotes ponalrestat $\times$ insulin $\times$ region interaction; $\mathrm{NS}=$ not significant; degrees of freedom (numerator, denominator) were 1,120 for ponalrestat treated rats (ARI), insulin treated rats (CIT) and $a \times c$ effects but 3,120 for all other effects; $B=$ perimeter length; $S=$ surface area; $\mathrm{V}=\operatorname{volume} ;(\mathrm{cr})=$ crypts $;(\mathrm{me})=$ muscularis externa $(\mathrm{pm})=$ primary $\operatorname{mucos} a ;(\mathrm{sm})=$ submucosa $;(\mathrm{v})=$ villi

At the same time that nutrient uptake increases, the total and specific activities of certain brush-border enzymes are elevated [5, 11, 32]. Sucrase activities at least are augmented by some mechanism which operates independently of luminal factors [11] and, again, has greater impact distally [32]. Part of the enhanced absorption and enzymic activity may be attributable to greater surface areas of microvilli [29].

Both increased absorption and increased enzymic activities are prevented or reduced by insulin therapy $[1,32,33]$. The present results demonstrate that insulin therapy also maintains structural quantities at levels found in age-matched animals, the single exception being villous surface/crypt volume. However, this ratio is not altered during STZ-diabetes [12].

In the present study, ponalrestat had a significant effect on body weight. Mean body weights between the untreated diabetic animals and diabetic animals treated with ponalrestat alone were not significantly different but values for the diabetic animals given insulin and ponalrestat were less than those for diabetic animals receiving insulin alone and for the agematched control animals. These findings for body weight follow the same pattern as that for tibial length reported previously for these animals [13]. They may reflect the observation [13] that whilst blood glucose concentrations were easy to control in diabetic animals receiving insulin alone, blood glucose levels were difficult to control in animals given ponalrestat and insulin.

Although ponalrestat has no beneficial effect on body weight and skeletal development, it is pertinent to remember that it is not intended to be a substitute for insulin or oral hypoglycaemic drugs. Ponalrestat administration helps to correct sorbitol, fructose and myo-inositol concentrations and axonal transport in the peripheral nerves of STZ-diabetic rats $[13,34,35]$. However, it does not correct structural abnormalities in nerve fibres [13] and the present study shows that structural changes in intestines are not corrected. Indeed, ponalrestat administration led to crypt hypertrophy beyond that found in untreated diabetic rats. This also contributed to a more voluminous submucosa in ponalrestat-treated diabetic rats.

Crypt hypertrophy during ponalrestat intervention cannot be explained as a response to luminal effects consequent on the mode of administration (orally by gavage). If this were so, then hypertrophy might be expected to occur also in animals given insulin and ponalrestat but this was not the case. How crypt hypertrophy relates to alterations in crypt cell hyperplasia, hypertrophy or migration along the crypt-villus axis remains to be investigated. Our unpublished findings have shown that crypt hypertrophy in untreated diabetic rats is associated with increases in crypt diameter (but not length) and numbers of mitotic figures. Ponalrestat administered alone produces further increases in numbers of mitoses.

Acknowledgements. The authors are grateful to Imperial Chemical Industries plc and Dr. D. Stribling for supporting our studies on the effects of ponalrestat (ICI 128436/MK538) and insulin intervention in experimental diabetes. We are also grateful to Professor E.J.Clegg for advice and criticism.

\section{References}

1. Olsen WA, Rosenberg IH (1970) Intestinal transport of sugars and amino acids in diabetic rats. $J$ Clin Invest 49:96-105

2. Schedl HP, Wilson HD (1971) Effects of diabetes on intestinal growth and hexose transport in the rat. Am J Physiol 220: $1739-1745$

3. Caspary WF (1973) Effect of insulin and experimental diabetes mellitus on the digestive absorptive function of the small intestine. Digestion 9: 248-263

4. Lal D, Schedl HP (1974) Intestinal adaptation in diabetes: amino acid absorption. Am J Physiol 227: 827-831

5. Nakabou Y, Ishikawa Y, Misaki A, Hagihira H (1980) Effect of food intake on intestinal absorption and hydrolases in alloxandiabetic rats. Metabolism 29: 181-185

6. Karasov WH, Diamond JM (1983) Adaptive regulation of sugar and amino acid transport by vertebrate intestine. Am $\mathbf{J}$ Physiol 245: G443-G462

7. Jervis EL, Levin RJ (1966) Anatomic adaptation of the alimentary tract of the rat to the hyperphagia of chronic alloxan-diabetes. Nature 210: 391-393

8. Stenling R, Hägg E, Falkmer S (1984) Stereological studies on the 
rat small intestinal epithelium. III. Effects of short-term alloxan diabetes. Virchows Arch (Cell Pathol) 47: 263-270

9. Nakabou Y, Okita C, Takano Y, Hagihira H (1974) Hyperplastic and hypertrophic changes of the small intestine. J Nutr Sci Vitaminol 20: 227-234

10. Miller DL, Hanson W, Schedl HP, Osborne JW (1977) Proliferation rate and transit time of mucosal cells in the small intestine of the diabetic rat. Gastroenterology 73: 1326-1332

11. Olsen WH, Korsmo H (1975) Enhancement of intestinal sucrase activity in experimental diabetes: the role of intraluminal factors. J Lab Clin Med 85: 832-837

12. Mayhew TM, Carson FL (1989) Mechanisms of adaptation in rat small intestine: regional differences in quantitative morphology during normal growth and experimental hypertrophy. J Anat 164: 189-200

13. Bhoyrul S, Sharma AK, Stribling D, Mirrlees DD, Peterson RG, Farber MO, Thomas PK (1988) Ultrastructural observations on myelinated fibres in experimental diabetes: effect of the aldose reductase inhibitor Ponalrestat given alone or in conjunction with insulin therapy. J Neurol Sci 85: 131-147

14. Mayhew TM, Sharma AK, McCallum KNC (1985) Effects of continuous subcutaneous insulin infusion on renal morphology in experimental diabetes. I. Blood glucose levels, body size, kidney weight and glomerulo-tubular morphometry. J Pathol 151: $147-155$

15. Mayhew TM, Lutchman M, Sharma AK (1988) Renal glomerular basement membrane thickening in experimental diabetes: a preliminary report on the effects of insulin and of an aldose reductase inhibitor. J Anat 158: 226-227

16. O'Neill S, Mayhew TM, Sharma AK (1988) Effects of insulin and an aldose reductase inhibitor on the volumes of kidney glomeruli and tubules in streptozotocin-diabetic rats. J Anat 161:250-251

17. Carson FL, Mayhew TM (1987) Effects of the aldose reductase inhibitor Statil on small bowel morphology in streptozotocindiabetic rats: crypt hypertrophy. J Anat 155: 243

18. Mayhew TM (1984) Geometric model of the rat intestinal mucosa for stereological evaluation of villus amplification factors. J Microse 135: 337-346

19. Mayhew TM, Middleton C (1985) Crypts, villi and microvilli in the small intestine of the rat. A stereological study of their variability within and between animals. J Anat 141:1-17

20. Mayhew TM, Middleton C, Ross GA (1988) Dealing with oriented surfaces: studies on villi and microvilli of rat small intestine. In: Reith A, Mayhew TM (eds) Stereology and morphometry in electron microscopy. Problems and solutions. Hemisphere Publishing, New York, pp 85-98

21. Weibel ER (1979) Stereological Methods, Volume 1, Practical Methods for Biological Morphometry. Academic Press, London

22. Mayhew TM (1988) A geometric model for estimating villous surface area in rat small bowel is justified by unbiased estimates obtained using vertical sections. J Anat 161: 187-193
23. Clarke RM (1972) The effect of growth and of fasting on the number of villi and crypts in the small intestine of the albino rat. J Anat 112: $27-33$

24. Forrester JM (1972) The number of villi in rat's jejunum and ileum: effect of normal growth, partial enterectomy, and tube feeding. J Anat 111:283-291

25. Miller S (1975) Experimental design and statistics. Methuen, London

26. Sokol RR, Rohlf FJ (1981) Biometry. The principles and practice of statistics in biological research. Freeman, San Francisco

27. Karasov WH, Debnam ES (1987) Rapid adaptation of intestinal glucose transport: a brush-border or basolateral phenomenon? Am J Physiol 16: G54-G61

28. Hopfer U (1975) Diabetes mellitus: changes in the transport properties of isolated intestinal microvillous membranes. Proc Nat Acad Sci 72: 2027-2031

29. Mayhew TM (1989) The striated brush border of intestinal absorptive epithelial cells: stereological studies on microvillous morphology in different adaptive states. J Elect Micr Tech, special issue (in press)

30. Debnam ES, Karasov WH, Thompson CS (1988) Nutrient uptake by rat enterocytes during diabetes mellitus: evidence for an increased sodium electrochemical gradient. J Physiol 397: 503-512

31. Caspary WF (1974) Increased ileal transport of bile salts in streptozotocin-diabetes. Bile salt absorption in rat small intestine. In: Dowling RH, Riecken EO (eds) Intestinal adaptation. Schattauer, Stuttgart New York, pp 195-203

32. Olsen W, Agresti HL, Lorenzsönn VW (1974) Intestinal disaccharidases in diabetic rats. In: Dowling RH, Riecken EO (eds) Intestinal adaptation. Schattauer, Stuttgart New York, pp 179-187

33. Caspary WF, Rhein AM, Creutzfeldt W (1972) Increase of intestinal brush-border hydrolases in mucosa of streptozotocin diabetic rats. Diabetologia 8: 412-414

34. Stribling D, Mirrlees DJ, Harrison HE, Earl DCN (1985) Properties of ICI 128436, a novel aldose reductase inhibitor, and its effects on diabetic complications in the rat. Metabolism 34: 336-344

35. Tomlinson DR, Townsend J, Fretten P (1985) Prevention of defective axonal transport in streptozotocin-diabetic rats by treatment with "Statil" (ICI 128436), an aldose reductase inhibitor. Diabetes 34: 970-972

Received: 14 March 1989

and in revised form: 23 May 1989

Dr. T. M. Mayhew

Department of Anatomy

Marischal College

University of Aberdeen

Aberdeen AB9 1 AS

Scotland UK 